\title{
Inhibitory Effects of Asiatic Acid on 7,12-Dimethylbenz[a]anthracene and 12-O-Tetradecanoylphorbol 13-Acetate-Induced Tumor Promotion in Mice
}

\author{
Byung Chul Park, Seung-Hwan Paek, Yoon-Seok Lee, Seung-Joo Kim, Eung-Seok Lee, \\ Han Gon Chol, Chul Soon Yong, and Jung-Ae Kim* \\ College of Pharmacy, Yeungnam University; 214-1 Dae-dong, Gyeongsan 712-749, Korea. \\ Received May 30, 2006; accepted August 28, 2006
}

Asiatic acid, a pentacyclic triterpene, has been reported to induce apoptosis of various human cancer cells. In the present study, we assessed the anti-tumor promoting effect of asiatic acid against 12- $O$-tetradecanoylphorbol 13-acetate (TPA)-mediated skin tumorigenesis in 7,12-dimethylbenz[a]anthracene (DMBA)-initiated ICR mice. Topical application of asiatic acid prior to each application of TPA resulted in a significant reduction in skin tumor formation. We also found that pre-application of asiatic acid alleviated TPA-induced $\left[{ }^{3} \mathrm{H}\right]$ thymidine incorporation, which is a conventional marker for skin tumor promotion. In addition, asiatic acid inhibited the TPA-induced generation of nitric oxide (NO) and expression of inducible NO synthase (iNOS) and cyclooxygenase-2 (COX-2), which are known to play important roles in tumor growth, especially in the promotion stage. In addition, topical application of aminoguanidine (AG), a selective iNOS inhibitor, and $N^{\mathrm{G}}$-nitro-L-arginine-methyl ester (NAME), another iNOS inhibitor, $30 \mathrm{~min}$ prior to TPA treatment significantly inhibited the TPA-induced COX-2 expression. These results suggest that asiatic acid may exert anti-tumorigenesis through inhibitory actions in NO and COX-2 signals. genesis

Key words asiatic acid; nitric oxide (NO); cyclooxygenase-2 (COX-2); 12-O-tetradecanoylphorbol 13-acetate (TPA); carcino-

Asiatic acid, a pentacyclic triterpene compound identified in the medicinal plant Centella asiatica, has shown various biological effects such as wound healing ${ }^{1)}$ and protective activities against UV-induced photoaging, ${ }^{2)}$ glutamate- or $\beta$ amyloid-induced neurotoxicity, ${ }^{3,4)}$ and hepatofibrosis. ${ }^{5)}$ Recently, research on asiatic acid has been more focused on its apoptosis-inducing activity in various cancer cells. ${ }^{6-8)} \mathrm{In}$ addition, it has also been reported that asiatic acid induces cell cycle arrest and anti-proliferative effects on human breast, gastric, and utrine cancer cells. ${ }^{9)}$ Moreover, asiatic acid has shown potentiating activity on the effect of the anticancer drug irinothecan, ${ }^{10)}$ suggesting promising potential of asiatic acid as a chemotherapeutic agent against cancer. However, despite of studies showing anticancer effect of asiatic acid in vitro, the effect of asiatic acid on carcinogenesis remains unknown.

Carcinogenesis is a multistep process comprising initiation, promotion, and progression stages arising as a result of chemical or biological insults to normal cells. Of the carcinogenesis processes, the tumor promotion stage is characterized by a sustained cellular proliferation of epidermal cells. There have been supporting data that nitric oxide (NO) acts a key signaling molecule in carcinogenesis. High and sustained generation of NO has been detected in various cancer tissues ${ }^{11)}$ and even in the urine from bladder cancer patients. ${ }^{12)}$ Furthermore, high level of iNOS expression has been correlated with tumor growth, ${ }^{13)}$ angiogenesis, ${ }^{14,15}$ and metastasis. ${ }^{16,17)}$ Many other studies have also demonstrated that NO enhances cyclooxygenase-2 (COX-2) enzyme activity as well as its expression. ${ }^{18-20)}$ In addition, COX-2 is now well known to mediate not only inflammatory reactions but the pathogenesis of various types of cancers. ${ }^{21-25)}$ Furthermore, combined administration of a selective inducible NO synthase (iNOS) inhibitor with celecoxib, a COX-2 inhibitor, has shown a synergistic chemopreventive effect on colon carcinogenesis. ${ }^{26)}$ Therefore, NO and COX-2 seem to be important molecular targets for chemoprevention.

The present study was undertaken to examine whether asiatic acid exerts chemopreventive effects on TPA-mediated skin carcinogenesis and to elucidate the molecular mechanisms underlying the anti-tumor promotion activity of asiatic acid in mouse skin using two-stage carcinogenesis, the most commonly used animal model for carcinogenesis with 12-Otetradecanoylphorbol 13-acetate (TPA), the most studied and known tumor promoter.

\section{MATERIALS AND METHODS}

Materials Aminoguanidine (AG) $N^{\mathrm{G}}$-nitro-L-argininemethyl ester (NAME), 12-O-tetradecanoylphorbol 13-acetate (TPA) and 7,12-dimethylbenz[ $a]$ anthracene (DMBA) were purchased from Sigma-Aldrich (St. Louis, MO, U.S.A.). Anti-human antibody for inducible nitric oxide synthase (iNOS) was purchased from Cayman (Ann Arbor, MI, U.S.A.); COX-2 antibody from Chemicon (Temecula, CA, U.S.A.).

Animal Treatment Female ICR mice at 6 weeks of age (from Hyochang Science, Umsung, Korea) were housed in well-ventilated polypropylene cages. The animal facility was maintained with a $12 \mathrm{~h} \mathrm{light} / 12 \mathrm{~h}$ dark cycle, a temperature of $24 \pm 2{ }^{\circ} \mathrm{C}$, and a relative humidity of $55 \pm 10 \%$. They were fed standard mouse chow and water ad libitum. The dorsal skin of the mice was shaved with an electric clipper (Joas, Seoul, Korea) followed by the application of hair-removing cream (Ildong Co., Ltd., Seoul, Korea) at least $2 \mathrm{~d}$ prior to the treatment. Only those mice that did not show any signs of hair regrowth were used for experiments. DMBA, TPA, AG, NAME, and asiatic acid were dissolved in $200 \mu \mathrm{l}$ of acetone 
and applied to the dorsal shaven areas.

Animal experiments were performed according to the institutional guidelines of the National Institute of Health and the University for the care and use of laboratory animals.

Two-Stage Mouse Skin Tumorigenesis At the start of the experiment, all groups of mice were treated on their shaven backs with a single topical application of DMBA (40 $\mu \mathrm{g}$ in $0.2 \mathrm{ml}$ of acetone). One week after initiation, Group I animals served as positive controls receiving acetone application followed by $5 \mu \mathrm{g}$ TPA in $0.2 \mathrm{ml}$ acetone. Group II animals received topical applications of $30 \mu \mathrm{mol}$ asiatic acid in $0.2 \mathrm{ml}$ acetone $1 \mathrm{~h}$ prior to application of $5 \mu \mathrm{g}$ TPA twice a week until termination of the experiment. Group III mice were treated as Group II mice, except that they were treated with $50 \mu \mathrm{mol}$ asiatic acid. Tumor incidence was determined by palpation on every 3rd day.

$\left[{ }^{3} \mathbf{H}\right]$ Thymidine Incorporation Isolation of epidermal DNA and determination of $\left[{ }^{3} \mathrm{H}\right]$ thymidine incorporation into cutaneous DNA were done by the method of Smart et al. ${ }^{27)}$ DMBA-initiated mice received topical application of TPA $1 \mathrm{~h}$ after the treatment with asiatic acid. Eighteen hours after treatment with TPA, the mice of all groups were given $\left[{ }^{3} \mathrm{H}\right]$ thymidine $(15 \mu \mathrm{Ci} /$ mouse $/ 0.2 \mathrm{ml}$ saline $)$ as an intraperitoneal injection and were killed after $2 \mathrm{~h}$ by cervical translocation. The skin tissues were quickly removed and cleaned free of extraneous material including dermis on ice, and homogenized in ice-cold water containing an equal volume of ice-cold trichloroacetic acid (10\%). The precipitate thus obtained was washed with cold trichloroacetic acid (5\%) and incubated with cold perchloric acid $(10 \%)$ at $4{ }^{\circ} \mathrm{C}$ overnight. After incubation, the mixture was centrifuged and the precipitate was washed with cold perchloric acid (5\%). The precipitate was dissolved in warm perchloric acid (10\%), followed by incubation in a boiling water bath for $30 \mathrm{~min}$. It was then filtered through Whatman 50 filter paper. The filtrate was used for $\left[{ }^{3} \mathrm{H}\right]$ thymidine counting in a liquid scintillation counter (Beckman, CA, U.S.A.). The amount of $\left[{ }^{3} \mathrm{H}\right]$ thymidine incorporated was expressed as $\mathrm{dpm} / \mu \mathrm{g}$ DNA.

Nitrite Assay The amount of nitrite was measured as an index of NO production by the Griess reaction. ${ }^{28)}$ Mouse skin was excised and homogenized in $50 \mathrm{~mm}$ potassium phosphate buffer ( $\mathrm{pH}$ 7.2). The homogenates were centrifuged at $25000 \mathrm{~g}$ for $20 \mathrm{~min}$ at $4{ }^{\circ} \mathrm{C}$. The supernatants were mixed with an equal volume of the Griess reagent (1\% sulphanilamide, $0.1 \%$ naphthylethylenediamine, $2.5 \%$ phosphoric acid) in duplicate on 96-well plates. After incubation at room temperature for $10 \mathrm{~min}$, the absorbance at $540 \mathrm{~nm}$ was measured by Microplate ELISA reader (Molecular Devices, CA, U.S.A.). The amount of nitrite formed was normalized to the protein content of the skin.

Western Blot Analysis For isolation of protein from mouse skin, the skin tissues cleaned free of dermis and fat on ice were immediately placed in liquid nitrogen and ground in a mortar. The ground tissue was lysed in $2 \mathrm{ml}$ ice-cold lysis buffer $(10 \mathrm{~mm}$ Tris-HCl, pH 7.6, $10 \mathrm{~mm}$ EDTA, $150 \mathrm{~mm}$ $\mathrm{NaCl}, 0.1 \%$ Nonidet P-40, $0.1 \mathrm{~mm}$ phenylmethylsulfonyl fluoride, $2 \mathrm{~mm}$ dithiothreitol, protease inhibitor cocktail). Lysates were centrifuged at $13000 \boldsymbol{g}$ at $4{ }^{\circ} \mathrm{C}$ for $15 \mathrm{~min}$, and supernatant proteins were separated on $14 \%$ or $15 \%$ SDSpolyacrylamide gels and transferred to nitrocellulose membrane at $200 \mathrm{~mA}$ for $1 \mathrm{~h}$. The membrane was blocked with $5 \%$ skim milk in a TBS buffer containing $0.1 \%$ Tween 20 (TBST) at room temperature for $1 \mathrm{~h}$. The membranes were immunoblotted with primary antibodies in TBST contained $5 \%$ skim milk for $2 \mathrm{~h}$. After three washings with TBST, the membranes were incubated with anti-goat IgG HRP conjugated secondary antibody (Santa Cruz Biotechnology Inc.). After three successive washings with TBST, the proteins were developed using a chemiluminescence assay kit and exposed to ECL film (Amersham Life Science, Buckinghamshire, England).

Statistical Analysis The two-tailed Student's $t$-test was employed to assess the significance of the data. The data are presented as mean \pm S.E.M. The level of significance was taken at $p<0.05$.

\section{RESULTS}

Inhibitory Effect of Asiatic Acid on DMBA/TPA-Induced Skin Tumor Promotion in Mice The reported activities of asiatic acid in cell cycle arrest, anti-proliferation, and the induction of apoptosis in various cancer cells in vitro
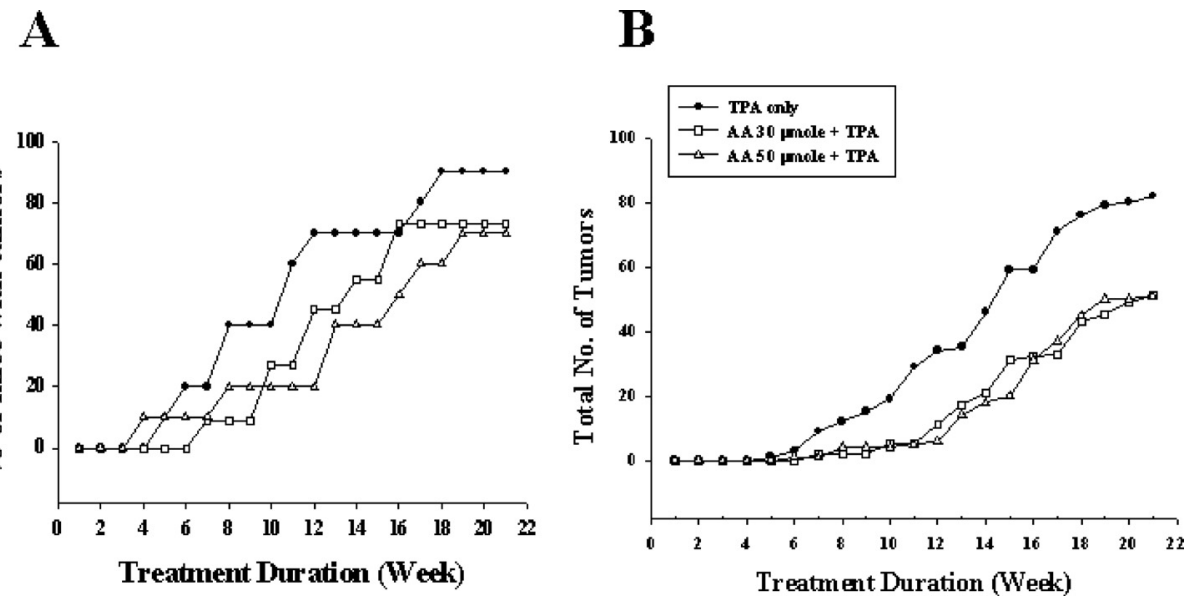

Fig. 1. Preventive Effects of Asiatic Acid on DMBA-Initiated and TPA-Promoted Mouse Skin Tumorigenesis

All the groups of mice were treated on the backs with a single topical application of DMBA ( $40 \mu \mathrm{g})$, and then, TPA ( $5 \mu \mathrm{g})$ twice a week for 15 weeks. Asiatic acid ( 30 or $50 \mu \mathrm{mol}$ ) and acetone as a vehicle were applied $1 \mathrm{~h}$ prior to every application of TPA for the experimental groups and control group, respectively. AA, DMBA, and TPA represent asiatic acid, 7,12-dimethylbenz $[a]$ anthracene, and 12-O-tetradecanoylphorbol 13-acetate, respectively. 


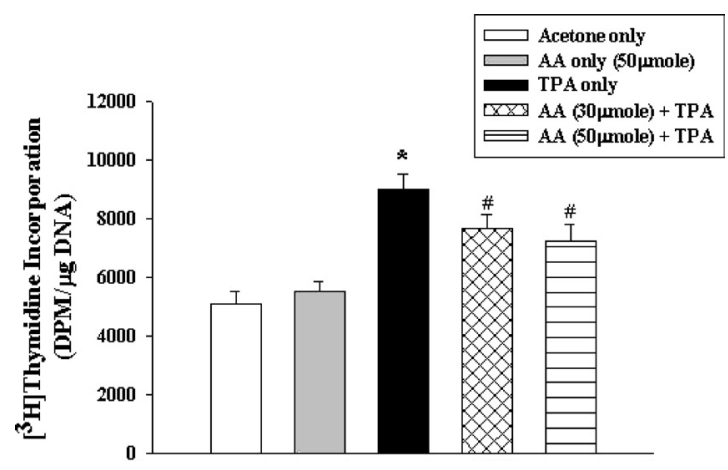

Fig. 2. Effect of Asiatic Acid on TPA-Mediated $\left[{ }^{3} \mathrm{H}\right]$ Thymidine Incorporation in Epidermal DNA

Mice were treated topically with 30 or $50 \mu \mathrm{mol}$ asiatic acid in acetone $1 \mathrm{~h}$ prior to TPA application. Control mice were treated with acetone in lieu of TPA. The $\left[{ }^{3} \mathrm{H}\right]$ thymidine was given $18 \mathrm{~h}$ after TPA treatment and $2 \mathrm{~h}$ thereafter, $\left[{ }^{3} \mathrm{H}\right]$ thymidine in corporation was measured. The data are expressed as mean \pm S.E.M. obtained from six mice/group. $* p<0.05$ compared to the acetone-treated control group. $\# p<0.05 \mathrm{com}-$ pared to the group treated with TPA.

reflect the chemopreventive potential of asiatic acid. In the present study, we examined the preventive effect of asiatic acid on tumor promotion in DMBA-initiated and TPA-promoted mouse skin. At 20 weeks after promotion in DMBAinitiated dorsal skin of mice, the tumor incidence in the control group was $90 \%$ (Fig. 1A). Topical application of asiatic acid prior to TPA treatment reduced the multiplicity of papillomas even though it had no significant effect on the tumor incidence. The average number of tumors per mouse in the control was 8 , which was significantly reduced to 5 by pretreatment with asiatic acid at 30 and $50 \mu \mathrm{mol}$ (Fig. 1B). In addition, we also examined the effect of pretreatment with asiatic acid on TPA-mediated enhancement of $\left[{ }^{3} \mathrm{H}\right]$ thymidine incorporation into mouse epidermal DNA, which is a conventional marker for skin tumor promotion. Treatment with TPA alone resulted in about a 2-fold enhancement in $\left[{ }^{3} \mathrm{H}\right]$ thymidine incorporation as compared with acetonetreated control mice (Fig. 2). However, the pre-application of asiatic acid significantly reduced TPA-induced $\left[{ }^{3} \mathrm{H}\right]$ thymidine incorporation.

Asiatic Acid Inhibits TPA-Induced NO Production and the Expression of iNOS and COX-2 in Mouse Skin It has been reported that the expression of iNOS and NO production is increased in various human tumors and TPA-induced experimental tumorigenesis. ${ }^{19)}$ Therefore, we investigated whether asiatic acid has a modulating effect on TPA-induced NO production. TPA increased NO production (Fig. 3A) and iNOS expression (Fig. 3B) in mouse skin, which, however, was significantly suppressed by the topical application of asiatic acid prior to TPA treatment. Since abundant evidence has shown that COX-2 expression is closely involved in carcinogenesis, we examined whether asiatic acid also reduces TPA-induced COX-2 expression. Concomitantly with the suppression of iNOS, pretreatment with asiatic acid decreased the expression of COX-2 induced by TPA (Fig. 3B). Next, we examined the possibility that decreased production of NO by asiatic acid was related to the suppression of TPAinduced COX-2 level. Topical application of AG, a selective iNOS inhibitor, or NAME, a nonselective blocker of NOS isoforms, prior to TPA treatment significantly prevented TPA-induced expression of COX-2 (Fig. 3C), of which effect

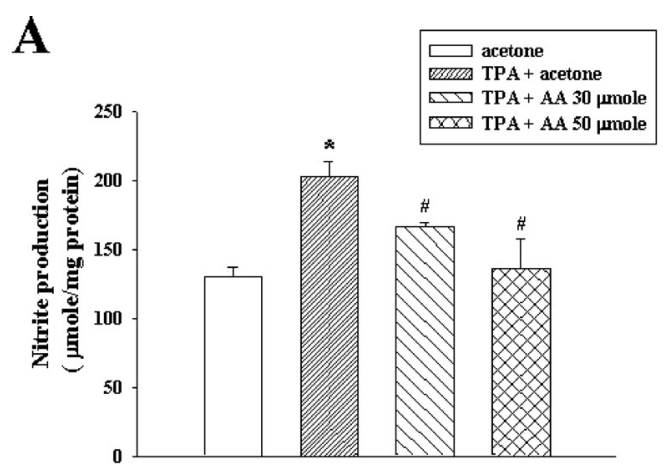

B

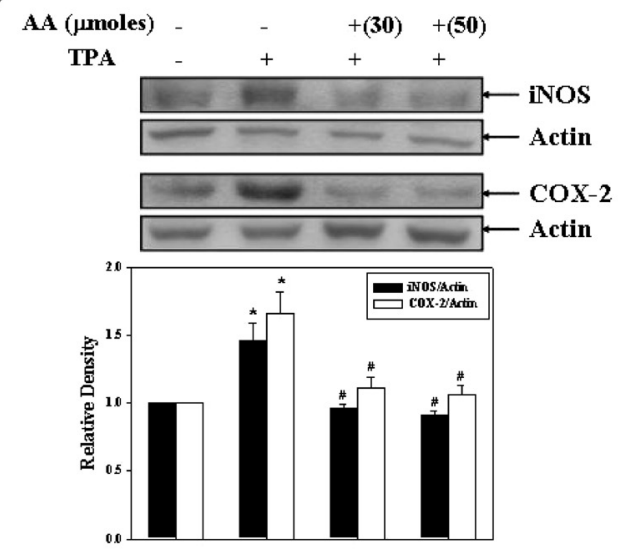

C
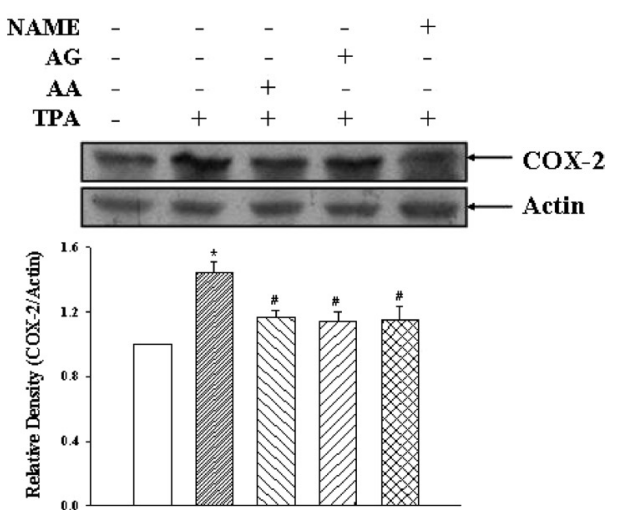

Fig. 3. Inhibitory Effects of Asiatic Acid on TPA-Induced NO Production and the Expression of iNOS and COX-2 in Mouse Skin

Female ICR mice were treated topically with acetone or asiatic acid $1 \mathrm{~h}$ prior to TPA on the back. In the experiments of (A), the amount of nitrite produced was measured $4 \mathrm{~h}$ after TPA treatment by the Griess reaction. The data are expressed as mean \pm S.E.M. obtained from six mice/group. In the experiments of (B), proteins extracted from the back skin of mice $1 \mathrm{~h}$ and $4 \mathrm{~h}$ after TPA application were analyzed for iNOS and COX2 , respectively. In the experiments of (C), mice were pretreated topically with either acetone or aminoguanidine $(30 \mu \mathrm{mol})$ and NAME $(10 \mu \mathrm{mol})$ for $30 \mathrm{~min}$, and asiatic acid for $1 \mathrm{~h}$ prior to TPA application. Mice were killed at $4 \mathrm{~h}$ after TPA application by cervical dislocation. The western blot is representative of four independent experiments. In the bar graph, the expression of iNOS and COX-2 was normalized to actin using a densitometer. AA, AG, and NAME represent asiatic acid, aminoguanidine, and $N^{\mathrm{G}}$-nitro-L-arginine-methyl ester, respectively. $* p<0.05$ compared to the acetonetreated control group. $\# p<0.05$ compared to the group treated with TPA.

was similar to that of asiatic acid.

\section{DISCUSSION}

Of the carcinogenesis processes, the tumor promotion stage is reversible and thus would be the proper point for 
chemoprevention. Our present study clearly demonstrated that asiatic acid inhibits tumor promotion in the mouse skin model of multistage carcinogenesis. The concentrations of asiatic acid used in this anti-tumor promotion study were over $\mathrm{IC}_{50}$ on cancer cell viability from our previous study. $\left.{ }^{7,8}\right)$ Asiatic acid has been shown to induce cell cycle arrest, antiproliferative effects on various cancer cells, and potentiating activity on the effect of the anticancer drug irinothecan. In addition to the in vitro antiproliferative activity in various cancer cells, our results suggest that asiatic acid may be a valuable candidate for the therapeutic intervention of cancers in the promotion stage.

Increased expression of iNOS and NO has been reported to play a key role in promoting carcinogenesis, and the NO signal would be a molecular target for chemoprevention. ${ }^{18,29)}$ Especially, an increasing amount of evidence has shown that iNOS expression is significantly correlated not only with size and histopathology of colorectal cancers but also with the expression of COX-2. ${ }^{30,31)}$ Moreover, overexpressed COX-2 has been considered to play a critical role in tumor promotion. COX-2 expression is up-regulated in a variety of human cancers. Experimental carcinogenesis studies in which TPA is most frequently used as skin tumor promoter have also shown that COX-2 protein, a phorbol ester-responsive gene product, is induced. Thus, COX-2 is a major molecular target of cancer chemoprevention, which approach is supported by studies showing that non-steroidal anti-inflammatory drugs and celebrex, a COX-2 selective inhibitor, protect against a variety of tumors. Our current result that asiatic acid inhibits the TPA-induced iNOS and COX-2 expression demonstrates that a molecular target of asiatic acid, as a cancer chemopreventive agent, may be COX-2. Furthermore, our results showed that the inhibitory effect of asiatic acid on the TPAinduced expression of iNOS and COX-2 was similar to that of topical pre-application of iNOS inhibitors, which indicates that the suppression of tumor promotion by asiatic acid may be related to nitric oxide signaling pathway leading to COX2 induction. In line with recent reports that TPA induces up-regulation of COX-2 expression in human epithelial cells, ${ }^{32,33)}$ asiatic acid may exert anti-tumor promotion through inhibitory actions in the NO-COX-2 pathway. Also, the possibility can not be excluded that anti-tumor promoting effects of asiatic acid may be mediated through an independent action on the expression of iNOS and COX-2.

Acknowledgement This work was supported by a grant (No. RTI04-01-04) from the Regional Technology Innovation Program of the Ministry of Commerce, Industry, and Energy (MOCIE).

\section{REFERENCES}

1) Maquart F. X., Chastang F., Simeon A., Birembaut P., Gillery P., Wegrowski Y., Eur. J. Dermatol., 9, 289-296 (1999).

2) Lee Y. S., Jin D. Q., Beak S. M., Lee E. S., Kim, J. A., Eur. J. Pharmacol., 476, 173-178 (2003).

3) Lee M. K., Kim S. R., Sung S. H., Lim D., Kim H., Choi H., Park H.
K., Je S., Ki Y. C., Res. Commun. Mol. Pathol. Pharmacol., 108, 75$86(2000)$

4) Jew S. S., Yoo C. H., Lim D. Y., Kim H., Mook-Jung I., Jung M. W., Choi H., Jung Y. H., Kim H., Park H. G., Bioorg. Med. Chem. Lett., 10, 119-121 (2000).

5) Dong M. S., Jung S. H., Kim H. J., Kim J. R., Zhao L. X., Lee E. S., Lee E. J., Yi J. B., Lee N., Cho Y. B., Kwak W. J., Park Y. I., Arch. Pharm. Res., 27, 512-517 (2004).

6) Hsu Y. L., Kuo P. L., Lin L. T., Lin C. C., J. Pharmacol. Exp. Ther, 313, 333-344 (2005).

7) Lee Y. S., Jin D. Q., Kwon E. J., Park S. H., Lee E. S., Jeong T. C., Nam D. H., Huh K., Kim, J. A., Cancer Lett., 186, 83-91 (2002).

8) Park B. C., Bosire K. O., Lee E. S., Lee Y. S., Kim J. A., Cancer Lett., 218, 81-90 (2005).

9) Yoshida M., Fuchigami M., Nagao T., Okabe H., Matsunaga K., Takata J., Karube Y., Tsuchihashi R., Kinjo J., Mihashi K., Fujioka T., Biol. Pharm. Bull., 28, 173-175 (2005).

10) Bunpo P., Kataoka K., Arimochi H., Nakayama H., Kuwahara T., Vinitketkumnuen U., Ohnishi Y., J. Med. Invest., 52, 65-73 (2005).

11) Kojima M., Morisaki T., Tsukahara Y., Uchiyama A., Matsunari Y., Mibu R., Tanaka M., J. Surg. Oncol., 70, 222-229 (1999).

12) Eijan A. M., Piccardo I., Riveros M. D., Sandes E. O., Porcella H., Jasnis M. A., Sacerdote De Lustig E., Malagrino H., Pasik L., Casabe A. R., J. Surg. Oncol., 81, 203-208 (2002).

13) Ahmad N., Srivastava R. C., Agarwal R., Mukhtar H., Biochem. Biophys. Res. Commun., 232, 328-331 (1997).

14) Ichinoe M., Mikami T., Shiraishi H., Okayasu I., Histopathology, 45 , $612-618$ (2004).

15) Larcher F., Murillas R., Bolontrade M., Conti C. J., Jorcano J. L., Oncogene, 17, 303-311 (1998).

16) Thomsen L. L., Miles D. W., Cancer Metastasis Rev., 17, 107-118 (1998).

17) Xie K., Fidler I. J., Cancer Metastasis Rev., 17, 55-75 (1998).

18) Salvemini D., Misko T. P., Masferrer J. L., Seibert K., Currie M. G., Needleman P., Proc. Natl. Acad. Sci. U.S.A., 90, 7240-7244 (1993).

19) Chun K. S., Cha H. H., Shin J. W., Na H. K., Park K. K., Chung W. Y., Surh Y. J., Carcinogenesis, 25, 445-454 (2004).

20) Mei J. M., Hord N. G., Winterstein D. F., Donald S. P., Phang J. M., FASEB J., 14, 1188-1201 (2000).

21) Fujita H., Koshida K., Keller E. T., Takahashi Y., Yoshimito T., Namiki M., Mizokami A., Prostate, 53, 232-240 (2002).

22) Ohno R., Yoshinaga K., Fujita T., Hasegawa K., Iseki H., Tsunozaki H., Ichikawa W., Nihei Z., Sugihara K., Cancer, 91, 1876-1881 (2001).

23) Ranger G. S., Jewell A., Thomas V., Mokbel K., J. Surg. Oncol., 88, $100-103(2004)$

24) Reddy B. S., Hirose Y., Lubet R., Steele V., Kelloff G., Paulson S., Seibert K., Rao C. V., Cancer Res., 60, 293-297 (2000).

25) Wolff H., Saukkonen K., Anttila S., Karjalainen A., Vainio H., Ristimaki A., Cancer Res., 58, 4997-5001 (1998).

26) Rao C. V., Indranie C., Simi B., Manning P. T., Connor J. R., Reddy B. S., Cancer Res., 62, 165-170 (2002).

27) Smart R. C., Huang M. T., Conney A. H., Carcinogenesis, 7, 18651870 (1986).

28) Green L. C., Wagner D. A., Glogowski J., Skipper P. L., Wishnok J. S., Tannenbaum S. R., Anal. Biochem., 126, 131-138 (1982).

29) Rao C. V., Mutat. Res., 555, 107-119 (2004).

30) Yagihashi N., Kasajima H., Sugai S., Matsumoto K., Ebina Y., Morita T., Murakami T., Yagihashi S., Virchows Arch., 436, 109-114 (2000).

31) Nosho K., Yoshida M., Yamamoto H., Taniguchi H., Adachi Y., Mikami M., Hinoda Y., Imai K., Carcinogenesis, 26, 892-899 (2005).

32) Chen B. C., Yu C. C., Lei H. C., Chang M. S., Hsu M. J., Huang C. L., Chen M. C., Sheu J. R., Chen T. F., Chen T. L., Inoue, H., Lin C. H., J. Immunol., 173, 5219-5228 (2004).

33) Chang M. S., Chen B. C., Yu M. T., Sheu J. R., Chen T. F., Lin C. H., Cell Signal., 17, 299-310 (2005). 